\title{
Commentaries on the letter to the editor
}

\section{Patricide and schizophrenia - A case report}

Comments about letter to the editor / Arch Clin Psychiatry. 2014;41(6):160

DOI: 10.1590/0101-60830000000036

\section{Daniel Martins de Barros}

Forensic Psychiatry and Psychology Center, Department and Institute of Psychiatry, Faculty of Medicine, University of São Paulo (FMUSP), São Paulo, Brazil.

The case report "Patricide and Schizophrenia"1 is very interesting and the topic highly relevant, once violence among psychiatric patients is quite a taboo, surrounded by prejudice, on the one hand, and misinformation on the other hand.

In the first place, it is noteworthy that psychiatric patients are more prone to be victim than perpetrator of crime and violence ${ }^{2}$. Thus, the main reason why people associate mental illness with aggressiveness is, above all, due to stigma and prejudice.

Nevertheless, one can not deny that severe psychotic patients, especially without proper treatment, are at a slightly but significantly higher risk of turning violent ${ }^{3}$. The risk is even higher when there is a comorbid abuse of substances ${ }^{3}$.

Killing the own father is a rare crime, but one that highly concerns psychiatrists. Whereas it is usually linked to a kind of family violence revenge if conducted by adolescents $s^{4}$, it is, if committed by an adult, often a case that involves a psychiatric patient, frequently suffering from schizophrenia ${ }^{5}$. Thus, this specific kind of homicide is, at least partially, a crime that could be prevented: if psychotic patients receive proper treatment, the symptoms can be controlled and, undoubtedly, a significant number of those crimes could be avoided.

\section{References}

1. Moscatello R. Patricide and schizophrenia - A case report. Arch Clin Psychiatry. 2014;41(6):159.

2. Teplin LA, McClelland GM, Abram KM, Weiner DA. Crime victimization in adults with severe mental illness: comparison with the National Crime Victimization Survey. Arch Gen Psychiat. 2005;62(8):911-2.

3. Van Dorn R, Volavka J, Johnson N. Mental disorder and violence: is there a relationship beyond substance use? Soc Psychiatry Psychiatr Epidemiol. 2012;47(3):487-503.

4. Newhill CE. Parricide. J Fam Violence. 1991;6(4):375-94.

5. Weisman AM, Sharma KK. Forensic analysis and psycholegal implications of parricide and attempted parricide. J Forensic Sci. 1997;42(6):1107-13.

\section{Gustavo Bonini Castellana}

Forensic Psychiatry and Psychology Center, Department and Institute of Psychiatry, Faculty of Medicine, University of São Paulo (FMUSP), São Paulo, Brazil.

The crime of parricide, as well as other violent acts, are not always associated with mental disorders. When this correlation exists, it is mainly associated with psychotic disorders.

Among the major psychotic syndromes, schizophrenia is considered the most important, both for the prevalence and chronicity of symptoms. Other psychotic syndromes, such as persistent delusional disorders and transiate psychotic disorders have a lower association with violent crimes, even though their prevalence in the general population are relevant.

The most recent psychiatric classifications tend to group diagnoses into broad categories. These groups aim to increase reliability among psychiatrists, losing, however, the specificity of the diagnosis. The actual possibility of dimensional diagnosis in DSM-V $V^{1}$ is nonetheless a recognition of the difficulty of grouping syndromes that occur with individual psychopathological phenomena in every single case.

In the reported case, the diagnosis of paranoid schizophrenia has some peculiarities, as violence against animals and against people - presented by the patient before the onset of psychotic symptoms - are not characteristic of the schizophrenic syndrome, and are usually associated with antisocial personality disorders or psychopathy

However, Kahlbaum described in $1885^{2}$, pre-schizophrenic symptoms characterized by oppositional behavior to family and society, with possible outbreaks of violence similar to those presented by psychopaths. The hebephrenia as the author titled, mimicking the psychopathy. But different from what occurs in disorders of personality, the evolution is compatible with a diagnosis of schizophrenia, with positive and negative symptoms present.

The recognition of this psychopathological description has importance not only in the performance of forensic psychiatrists, but also in everyday psychiatric clinic. The neglect of classical psychopathology in outpatient psychiatry can lead psychiatrists to remain restricted to the use of standardized scales and superficial behavior analysis, leaving to observe these nuances psychopathological.

The case described ${ }^{3}$ is typical for those who work as a forensic psychiatrist, and is fruitful for reflection of the complex relationship between mental illness and violence. Moreover, his account is a singular testimony of psychopathological wealth and biographical poverty that is still present in the custody and treatment hospitals in Brazil.

\section{References}

1. American Psychiatric Association (APA). DSM-V - Manual Diagnóstico e Estatístico de Transtornos Mentais. 5th ed. rev. Porto Alegre: Artmed; 2014.

2. Ey H, Bernard P, Brisset C. Manual de psiquiatria. Rio de Janeiro: Ed Masson do Brasil Ltda.; 1981.

3. Moscatello R. Patricide and schizophrenia - A case report. Arch Clin Psychiatry. 2014;41(6):159. 